\title{
Characterizing the changing environment of crop- land in the Songnen Plain, Northeast China, from 1990 to 2015
}

\author{
ZHANG Yuan ${ }^{1,2},{ }^{*}$ ZANG Shuying ${ }^{3}$, SUN Li ${ }^{3}$, YAN Binghe ${ }^{3}$, YANG Tianpeng ${ }^{1}$, \\ YAN Wenjia ${ }^{1}$, MEADOWS E Michael ${ }^{1,4}$, WANG Cuizhen ${ }^{5}$, QI Jiaguo ${ }^{6}$ \\ 1. Key Laboratory of Geographic Information Science (Ministry of Education), School of Geographic Sciences, \\ East China Normal University, Shanghai 200241, China; \\ 2. Institute of Eco-Chongming, East China Normal University, Shanghai 200062, China; \\ 3. Key Laboratory of Remote Sensing Monitoring of Geographic Environment, College of Heilongjiang Province, \\ Harbin Normal University, Harbin 150025, China; \\ 4. Department of Environmental \& Geographical Science, University of Cape Town, Rondebosch 7701, South \\ Africa; \\ 5. Department of Geography, University of South Carolina, Columbia, SC 29208, USA; \\ 6. Center for Global Change and Earth Observations and Department of Geography, Michigan State University, \\ East Lansing, MI 48824, USA
}

\begin{abstract}
Quantitative characterization of environmental characteristics of cropland (ECC) plays an important role in maintaining sustainable development of agricultural systems and ensuring regional food security. In this study, the changes in ECC over the Songnen Plain, a major grain crops production region in Northeast China, were investigated for the period 1990-2015. The results revealed significant changes in climate conditions, soil physical properties and cropland use patterns with socioeconomic activities. Trends in climate parameters showed increasing temperature $\left(+0.49^{\circ} \mathrm{C} /\right.$ decade, $\left.\mathrm{p}<0.05\right)$ and decreasing wind speed $(-0.3 \mathrm{~m} / \mathrm{s} /$ decade, $p<0.01)$ for the growing season, while sunshine hours and precipitation exhibited non-significant trends. Four topsoil parameters including soil organic carbon (SOC), clay, bulk density and $\mathrm{pH}$, indicated deteriorating soil conditions across most of the croplands, although some do exhibited slight improvement. The changing amplitude for each of the four above parameters ranged within -0.052 to $0.029 \mathrm{~kg} \mathrm{C} / \mathrm{kg},-0.38$ to 0.30 , -0.60 to $0.39 \mathrm{~g} / \mathrm{cm}^{3},-3.29$ to 2.34 , respectively. Crop production significantly increased (44.0 million tons) with increasing sown area of croplands ( 2.5 million ha) and fertilizer application ( 2.5 million tons). The study reveals the dynamics of ECC in the Songnen Plain with intensive cultivation from 1990 to 2015. Population growth, economic development, and policy reform are shown to strongly influence the spatiotemporal changes in cropland characteristics. The study potentially provides valuable scientific information to support sustainable
\end{abstract}

Received: 2018-01-10 Accepted: 2018-04-10

Foundation: National Natural Science Foundation of China, No.41571410, No.41571199, No.41401589

Author: Zhang Yuan (1975-), PhD and Associate Professor, specialized in remote sensing of agroecology.

E-mail: yzhang@geo.ecnu.edu.cn

"Corresponding author: Zang Shuying (1963-), Professor, specialized in remote sensing of land.

E-mail: syzang@yahoo.com 
agroecosystem management in the context of global climate change and national socioeconomic development.

Keywords: Songnen Plain; environmental characteristics of cropland; climate change; soil properties; grain yield

\section{Introduction}

Cropland is a complex agroecosystem in which climate, soil and human activities are principal functional determinants (Bohlen and House, 2009). Reciprocal interactions between these elements combine to determine yields in response to environmental and management factors (Figure 1). Climate and soil provide the required energy and nutrients for crop growth, while human activity can adjust both cropping practices and soil management such as tillage and application of fertilizers. Variations in climate and soil conditions directly affect both cropping regimes and management practices for croplands. In turn, intensive cultivation, especially over extended periods, may alter soil properties which then influence crop production. Changes in soil characteristics result in a range of environmental impacts, including the moisture regime, the carbon budget at the climate-soil interface and even local or regional climate (Hillel and Rosenzweig, 2011, 2013). To understand such a complex system, there is a need to analyze the longer-term dynamics of environmental characteristics of cropland (ECC) (Bakker et al., 2011). At present, it has become more feasible due to the increasing availability of big data analysed using robust methods and yielding predictive insights. Quantification of spatiotemporal changes in environmental factors in croplands is critical for understanding their interactions and for promoting their sustainable management in the future.

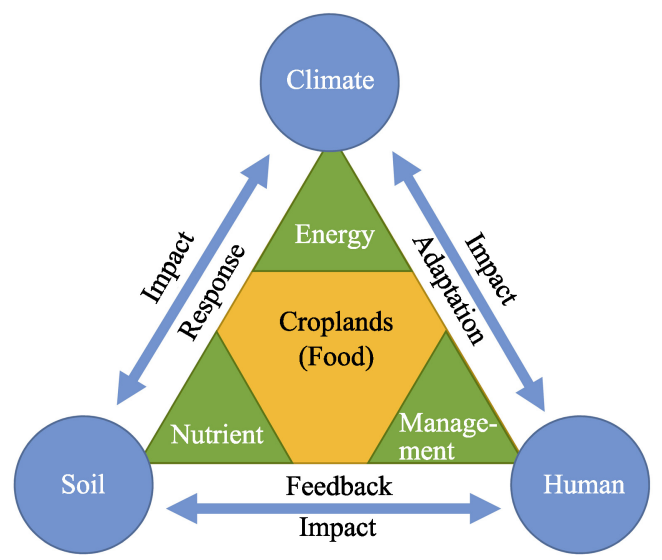

Figure 1 Conceptual diagram of a cropland ecosystem

As a typical cropland ecosystem, The Songnen Plain in Northeast China has experienced evident changes in the agricultural environment since the early 1990s. Climate changes could exert various (positive or negative) impacts on cropland cultivation and agroecosystem structure and function (IPCC, 2007; Li et al., 2012). In the Songnen Plain, increasing growing season temperature may further result in the northern land becoming more suitable for cultivation. This potentially stimulates farmers to reclaim grassland, wetlands and woodlands for agriculture (Wang et al., 2011; Huang et al., 2012; Qiu et al., 2016). On the other hand, climate warming may have negative effects on crop production because of increased evapotranspiration (Schauberger et al., 2017). Any resulting soil moisture deficiency may induce water stress for rain-fed crops. In the Songnen Plain, seasonal drought is most frequent during spring and autumn (Wang et al., 2004; Huang and Wang, 2010). Extended periods of drought over large areas are frequently associated with severe losses of agricultural production (Song et al., 2014a).

Cropland soils are highly susceptible to changes in climate. Mean temperature and pre- 
cipitation are important in influencing SOC formation and decomposition (Quideau et al., 2001; Wagai et al., 2008; Podwojewski et al., 2011). Many previous studies have found that SOC content decreases with rising temperature (Burke et al., 1989; Jobbágy and Jackson, 2000; Dai and Huang, 2006; Homann et al., 2007; Fantappiè et al., 2011), while there is less consensus regarding the relationship between SOC and changing precipitation (Alvarez and Lavado, 1998; Wang et al., 2010a; Xia et al., 2010; Zhou et al., 2016). Land use/cover change is an important determinant of soil carbon changes (Richter and Houghton, 2011) but different conclusions have been drawn in this regard. Carbon loss in agricultural soils in the semi-arid and semi-humid regions of Northeast China has certainly been widely reported (Piao et al., 2009; Wu et al., 2003; Zhuang et al., 2007; Xie et al., 2007). In the Songnen Plain, SOC has declined significantly due to reclamation and tillage over an extended period (Wang et al., 2010b; Jiang et al., 2016).

Since the 1990s, cropland area in the Songnen Plain increased significantly (JSB, 2016; HSB, 2016). Many grasslands, sandy lands and abandoned farmlands have been reclaimed or reused by farmers in pursuing greater economic returns. Conversion of grassland to land for agricultural purpose has in fact been a convention for many decades in order to meet the socioeconomic demand (Wang et al., 2011). Tan et al. (2014) recorded that both cropped area and yield of maize have risen by more than $50 \%$ in southern part of the Songnen Plain since 2000. The increased grain yield accompanied the growth in sown area of arable lands, the input of, for example, fertilizer was also favoured by greater efficiency of management practices (Meng et al., 2016).

However, there are significant challenges to the ongoing sustainability of agriculture in the Songnen Plain. It is anticipated that the rate of growth in cropland area will decline gradually in China as economic development and urbanization progress (Zhang and Wang, 2014). The agro-pastoral ecotone in the west of Songnen Plain is highly vulnerable to climate dynamics (frequent floods and drought) and land degradation (in particular salinization and alkalinization) (Wen et al., 2012). Moreover, ongoing population growth in China will result in increasing demand for food resources from croplands suitable for cultivation (National Bureau of Statistics of China, 2016). In addition, regionally unbalanced economic development has exerted comprehensive pressures on the cropland productivity (Chen et al., 2011). Therefore, understanding the dynamics of ECC in the Songnen Plain is essential for facilitating sustainable development of agriculture and ensuring national food security in the future, more especially against the backdrop of ongoing population growth and climate change (Tilman et al., 2002).

This study aims to develop a synthesis of trends in environmental and cropland dynamics, to explain the processes underlying the spatiotemporal trends in terms of changes in climate, soil and land use policy and management factors for the period from 1990 to 2015 . The paper establishes, in relation to the 25 -year period, the following objectives: 1) To describe changing climate, as exhibited by measures of mean annual temperature, precipitation and wind conditions, and to compare these parameters with those for the May to October growing season in particular; 2) to identify changing soil properties as indicated by measurements of soil organic carbon, clay content, bulk density and $\mathrm{pH}$; and 3) to characterize the changes in cropland and to compare the satellite-derived land use dynamics with crop production figures based on available agronomic data. This study ultimately targets the goal of improv- 
ing the management of cropland resources in the Songnen Plain against a background of future climate change.

\section{Data and methods}

\subsection{Study area}

As one of three major plains in Northeast China, the Songnen Plain occupies approximately $2.375 \times 10^{5} \mathrm{~km}^{2}$ and lies between $121^{\circ} 40^{\prime} \mathrm{E}-128^{\circ} 30^{\prime} \mathrm{E}$ and $42^{\circ} 30^{\prime} \mathrm{N}-51^{\circ} 20^{\prime} \mathrm{N}$ (Figure 2). Elevation ranges from $80 \mathrm{~m}$ to $1670 \mathrm{~m}$ above sea level, the lower elevation central plain being surrounded by Changbai Mountains to the east, Da Hinggan Mountains to the west and Xiao Hinggan Mountains to the north. The region experiences a typical temperate, semi-arid continental monsoon climate with annual mean temperature of $2-6^{\circ} \mathrm{C}$ and annual precipitation of $400-600 \mathrm{~mm}, \sim 80 \%$ of which concentrates in summer (June through September). Two major rivers, the Songhuajiang and Nenjiang, traverse the plain through the north and east, and central parts, respectively. These rivers and their associated tributaries (the second Songhuajiang River, Taoer River, Huolin River, Wuyuer River, Lalin River, Hulan River and Raohe River, etc.) together yield abundant water resources that supply the entire plain. The plain occupies one of the major black soil zones in the world (Zhang et al., 2003). The main soil types include black soil (Luvic Phaeozem, FAO), chernozem (Haplic Chernozem, FAO), meadow soil (Eutric Vertisol, FAO), Solonetz (Solonetz, FAO), Solonchak (Solonchak, FAO) and aeolian soil (Arenosol, FAO) (Liu et al., 2009). It is considered to be one of the largest state commercial grain bases in China (Leipnik et al., 2014). Total area of croplands in 2015 approximated 11.5 million ha, accounting for some $7 \%$ of the country's total crop

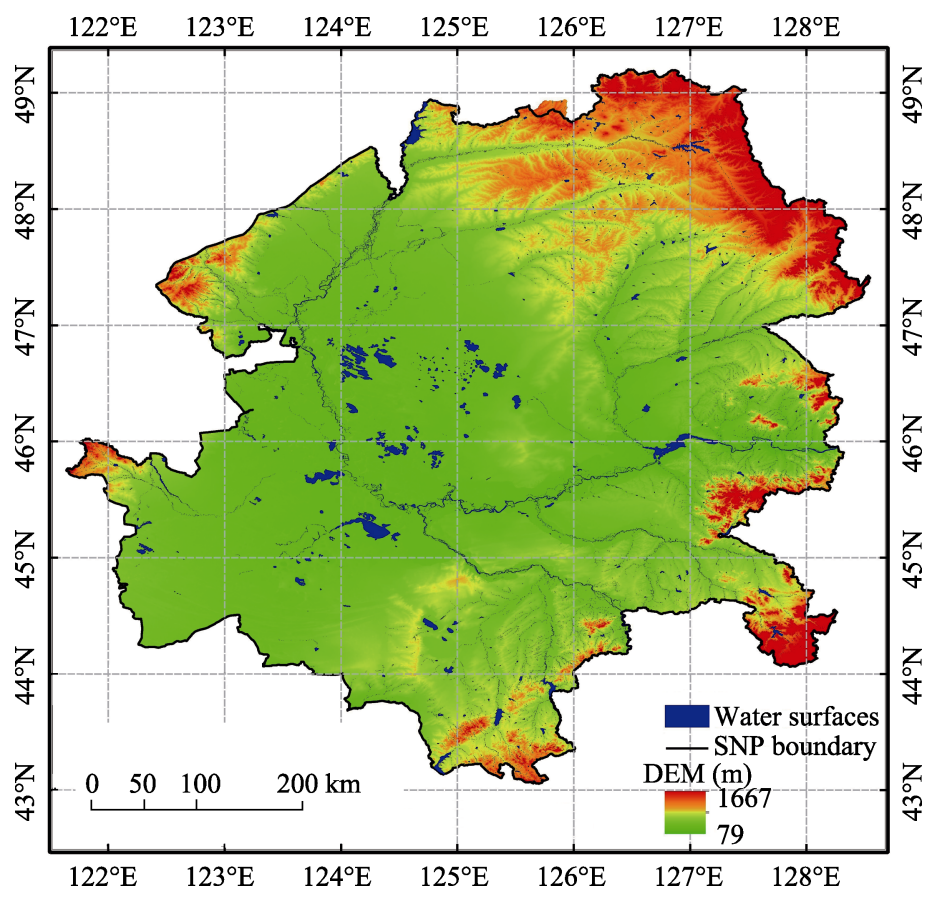

Figure 2 The Songnen Plain, Northeast China and its digital elevation model (DEM) 
cropping area ( $\sim 166.37$ million ha). The annual grain yield of 71.4 million tons (2015) accounts for about $11.5 \%$ of national total (621.44 million tons) (NBS, 2016). The main crops are maize (Zea mays L.), rice (Oryza sativa L.), and soya (Glycine max L.), and a single-season cropping system was the dominant crop management practice in this region (Wang et al., 2003). The total population of the Songnen Plain is more than 37.97 million in 2015 (JSB, 2016; HSB, 2016).

\subsection{Climate data}

The climate dataset (1990-2015) comprises four parameters, namely, mean annual temperature, sunshine hours, precipitation, and mean wind speed. The data were acquired from 29 basic weather stations of the Meteorological Information Center affiliated to China Meteorological Administration (Access to China Meteorological Data Sharing Service System, http://data.cma.gov.cn/). For each of the stations covering the Songnen Plain, annual mean temperature $(\mathrm{T})$, total sunshine hours $(\mathrm{S})$, annual total precipitation $(\mathrm{P})$ and annual average wind speed $(\mathrm{W})$ were initially computed.

In the Songnen Plain, growing season of crops is generally within the frost-free period from early May to late September (Wang et al., 2003) which may be extended under the condition of recent climate warming (Chen et al., 2005). Therefore, this study also focuses on characterizing climate conditions in the growing season (May to early October). A separate sub-set of climate data, using only meteorological parameters in May to October, was established to represent conditions during the crop growing season. An analysis of the means of each of the climate parameters for 29 stations was conducted in order to characterize climate dynamics over the past 25 years.

A trend analysis algorithm, the Mann-Kendall (MK) trend test (Mann, 1945; Kendall, 1975; Hirsch et al., 1982), was then implemented to explore spatiotemporal dynamics of the various climate parameters. The statistical analysis within the MK test was performed using RStudio (Version 0.99 .903$)$ yielding $Z$ values at various levels of statistical significance $(0.2$, $0.1,0.05,0.02,0.01$ and 0.001$)$.

\subsection{Soil data}

Two soil datasets were used in this study in order to characterize the soil conditions in both the recent past and present day respectively. Historical soil data were derived from the dataset obtained by the Institute of Soil Science, Chinese Academy of Sciences, and which was compiled based on the second National Soil Survey conducted between 1979-1985. This dataset contains multi-layer soil properties (e.g. organic matter, $\mathrm{pH}$ and bulk density), soil texture (sand, silt and clay) at various profile levels at a spatial resolution of $10 \mathrm{~km} \times 10 \mathrm{~km}$ (Shi et al., 2004; Yu et al., 2007). Soil organic carbon values (SOC) were calculated by multiplying the organic matter content by a conversion coefficient of 0.58 (Périé and Ouimet, 2008). Historical soil data are used as a benchmark to indicate conditions of Songnen soils in the nominal year 1990, and as representative of soil responses to the relatively consistent agricultural regimes during the period of 1980-1990.

The second soil dataset was acquired in a regional survey conducted by a research group at Harbin Normal University, China. In order to avoid the influences of ploughing and fertilization on the soil characteristics, soil samples of $0-10 \mathrm{~cm}$ were collected from the end of 
April to early May 2015. In all, 993 soil samples from 331 sites (three samples per site) were obtained across the croplands of the Songnen Plain (Figure 3). Sample sites, GPS-located, were located a minimum of $10 \mathrm{~m}$ away from roads. Samples were air dried, ground and sieved for subsequent determination of four key soil properties ( $\mathrm{SOC}, \mathrm{pH}$, bulk density and mechanical composition). SOC was analyzed using a Multi N/C 2100 TOC analyzer (Analytik Jena AG, Germany). A pH meter (REX PHSJ-3F, INESA Instrument Ltd., China) was used to measure the soil acidity. Soil bulk density was determined by measuring the original volume of each soil sample and the dry mass of it after oven-drying at $105^{\circ} \mathrm{C}$. Soil mechanical composition (clay, silt, sand) was measured using a Mastersizer 2000 particle size analyzer (Marvern Instruments Ltd., United Kingdom). The soil clay fraction was determined by the percentage of particles with size $<0.002 \mathrm{~mm}$ in accordance with the USDA classification system (Lu, 2000).

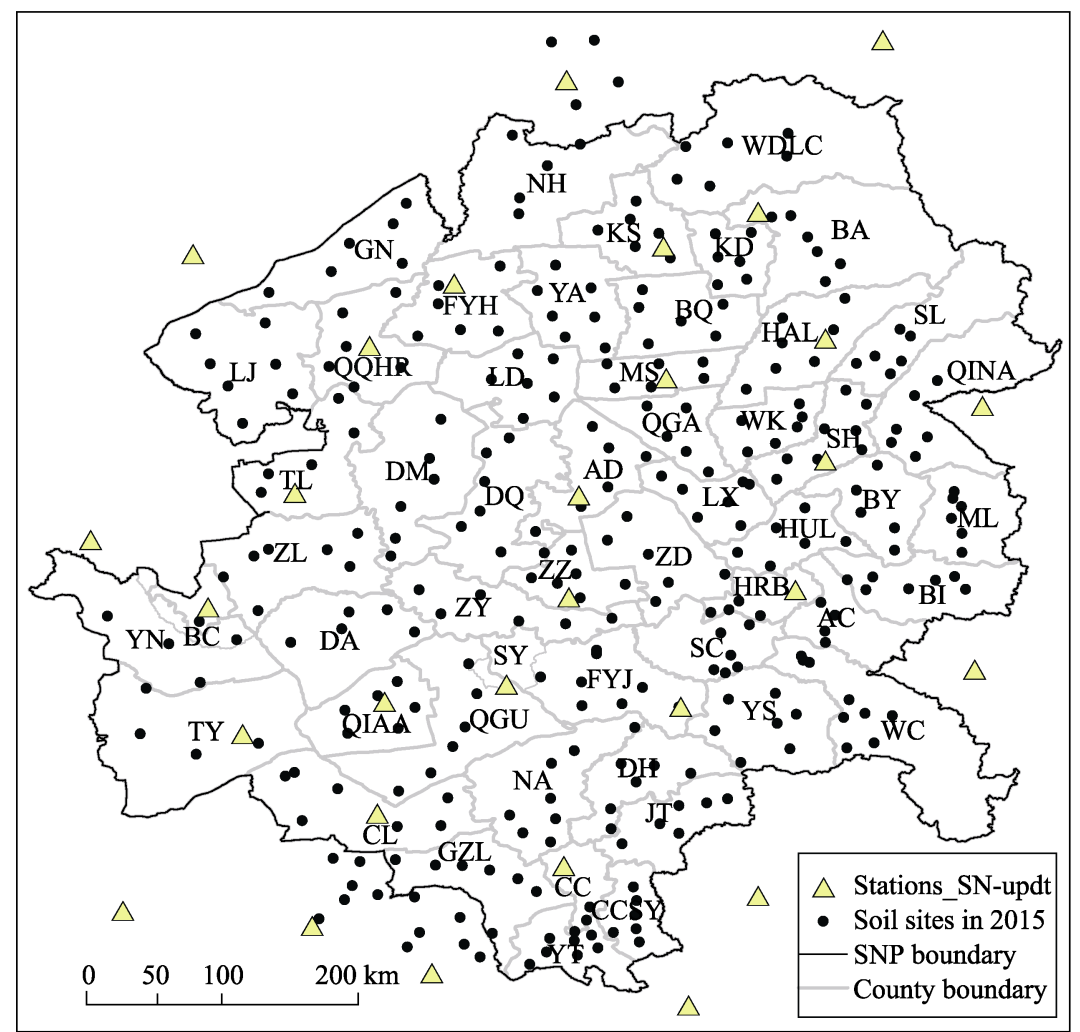

Figure 3 Spatial distribution of climate stations and soil sampling sites observed in 2015

The inverse distance weight (IDW) method (Shepard, 1968) was utilized to interpolate soil parameters using all 331 sampling sites for constructing the spatial distribution maps. The soil parameter maps were resampled into grid size of $10 \mathrm{~km}$ in consistency with that of the nominal 1990 soil maps. In this study, four major parameters of the topsoil $(0-10 \mathrm{~cm})$, SOC $(\mathrm{kg} \mathrm{C} / \mathrm{kg}), \mathrm{pH}$, bulk density $\left(\mathrm{g} / \mathrm{cm}^{3}\right)$ and clay fractional content (\%) were mapped for both historical and contemporary soils, facilitating the consideration of spatiotemporal changes in topsoil physical properties of croplands over a 25 -year period of intensive cultivation. 


\subsection{Land use types and cropping information}

In order to characterize the changing agricultural land use situation, remote sensing images from Landsat-5 (1990) and Landsat-8 (2015/2016), accessed via http://glovis.usgs.gov/, were classified by visual interpretation in ArcGIS software (ESRI Co., Ltd) three main categories, paddy fields, other cultivated lands and urban and rural built-up areas (Table 1). The resultant classified maps (see below section 3.3) characterize the spatiotemporal dynamics of three major land use types from 1990 to 2015. Additionally, statistical data derived from Jilin Statistical Yearbook (1991-2016) and Heilongjiang Statistical Yearbook (1991-2016) were employed to investigate cropland dynamics, as well as grain production and fertilizer application in the Songnen Plain. Total cropped area of croplands, fertilizer consumption and grain yield were calculated for each of the 53 administrative counties or cities, of which 18 counties are located in Jilin Province and other 35 counties in Heilongjiang Province.

Table 1 Landsat-5 TM images acquired in 1990 and Landsat-8 OLI in 2015/2016 for cropland mapping

\begin{tabular}{|c|c|c|c|c|c|c|}
\hline \multirow{2}{*}{ RS imagery } & \multirow{2}{*}{ Path No. } & \multicolumn{5}{|c|}{ Acquisition date for each row No. } \\
\hline & & $\mathrm{R} 26$ & $\mathrm{R} 27$ & $\mathrm{R} 28$ & R29 & $\mathrm{R} 30$ \\
\hline \multirow{5}{*}{$\begin{array}{l}\text { Landsat-5 } \\
\text { TM }\end{array}$} & P117 & - & $\begin{array}{l}1990 / 6 / 20 \\
1990 / 8 / 07\end{array}$ & $\begin{array}{c}1990 / 6 / 20 \\
1990 / 8 / 07\end{array}$ & $1990 / 8 / 07$ & - \\
\hline & P118 & $1990 / 6 / 27$ & $1990 / 6 / 27$ & $\begin{array}{c}1990 / 6 / 27 \\
1990 / 9 / 15\end{array}$ & $\begin{array}{c}1990 / 6 / 27 \\
1990 / 9 / 15\end{array}$ & $\begin{array}{l}1990 / 6 / 27 \\
1990 / 9 / 15\end{array}$ \\
\hline & P119 & $\begin{array}{c}1990 / 7 / 04 \\
1990 / 9 / 06\end{array}$ & $\begin{array}{l}1990 / 7 / 20 \\
1990 / 9 / 06\end{array}$ & $\begin{array}{l}1990 / 7 / 20 \\
1990 / 9 / 06\end{array}$ & $1990 / 7 / 04$ & - \\
\hline & P120 & $1990 / 6 / 25$ & $1990 / 6 / 25$ & $1990 / 6 / 25$ & $1990 / 7 / 11$ & - \\
\hline & P121 & - & - & $1990 / 8 / 03$ & - & - \\
\hline \multirow{5}{*}{$\begin{array}{l}\text { Landsat-8 } \\
\text { OLI }\end{array}$} & P117 & - & $2015 / 9 / 29$ & $2015 / 5 / 24$ & $2015 / 5 / 24$ & - \\
\hline & P118 & $2016 / 5 / 17$ & $2016 / 5 / 17$ & $2016 / 5 / 17$ & $2016 / 5 / 17$ & $2016 / 5 / 17$ \\
\hline & P119 & $2015 / 9 / 24$ & $2015 / 5 / 22$ & $2015 / 5 / 22$ & $2015 / 5 / 22$ & $2015 / 6 / 23$ \\
\hline & P120 & $2016 / 5 / 31$ & $2016 / 5 / 31$ & $2016 / 5 / 31$ & $2016 / 5 / 31$ & - \\
\hline & P121 & - & - & $2015 / 6 / 21$ & - & - \\
\hline
\end{tabular}

\section{Results}

\subsection{Changes in climatic conditions of croplands}

On first inspection of the climate parameters, there appears no marked trends in mean annual temperature, sunshine hours and precipitation from 1990 to 2015, although average wind speed does show a strong decreasing trend over the period (Figure 4). On closer scrutiny, however, some interesting temporal trends in key climate variables are evident that are likely to have an influence on crop productivity. For example, prior to 2001, annual precipitation exhibits a general decreasing trend, with the exception of 1998 which experienced extreme flooding due to the El Niño of 1997-1998 (McPhaden, 1999). From 2001 onwards, the mean annual precipitation appears to be on the increase. Sunshine hours gradually increase between 1990 and 2001, but decrease markedly to 2015. Sunshine hours in 1998, 2003 and 2013 are somewhat lower, associating with more cloudy and/or rainy days (Figures 4a and 4b). 
For the growing season, the same four climate parameters in the dataset are characterized just for the May to October period (Figures 4c and 4d). Among them, three variables (precipitation, sunshine hours and wind speed) exhibit similar trends for the growing season (May to October) as the annual dynamics in general. However, a growing season warming trend is evident from 1990 to 2002, followed by a period (2003 to 2015) of relatively stable temperatures. In general, the mean temperature increase $0.49^{\circ} \mathrm{C} /$ decade $(p<0.05)$ and wind speed decrease $0.3 \mathrm{~m} / \mathrm{s} /$ decade $(\mathrm{p}<0.01)$ for the growing season are found from 1990 to 2015 (Figures 4c and 4d).
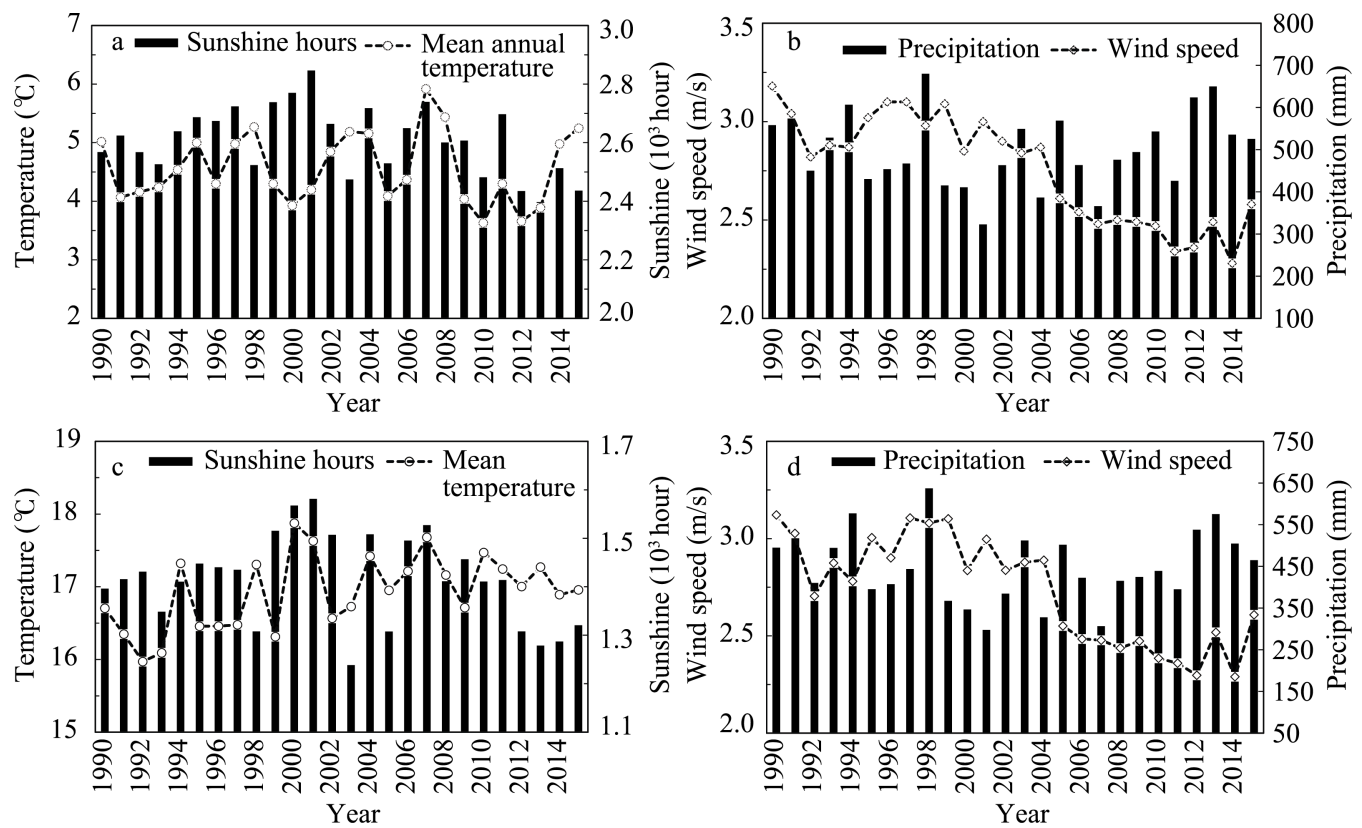

Figure 4 Climate parameters in the Songnen Plain from 1990 to 2015. (a) annual sunshine hours and annual mean temperature, (b) annual precipitation and annual mean wind speed, (c) sunshine hours and mean temperature in the growing season (May-October), and (d) precipitation and mean wind speed in the growing season

The results of the Mann-Kendal trend analysis for the growing season are presented in Figure 5, which illustrates the spatial distribution of $\mathrm{Z}$-values across the region during the time period of 1990-2015. More positive Z-values are interpreted as indicating parameter values increasing over time, as opposed to lower (or more negative) values (Hirsch et al., 1982). There is a clear increasing trend in mean temperature during the growing season (Figure 5a), while wind speed declines (Figure 5d). The increase in temperature is especially marked in counties of the northeastern, eastern, southwestern and western parts of the region. Growing season rainfall appears to vary little. It exhibits a slight decreasing trend over the whole plain, with the exception of some areas in the west and the south (Figure 5c). Sunshine hours also vary little, with some areas in the eastern and the northern-central parts experiencing a slight decrease (Figure $5 \mathrm{~d}$ ).

\subsection{Changes in cropland soil conditions}

Soil conditions are indicated in the interpolated distribution maps for both 1990 and 2015 (Figure 6). They show that SOC and clay content are generally higher in the north and east, mainly the forestlands (Figures 6a1, 6b1, 6a2 and 6b2). Whereas soil bulk density and $\mathrm{pH}$ 


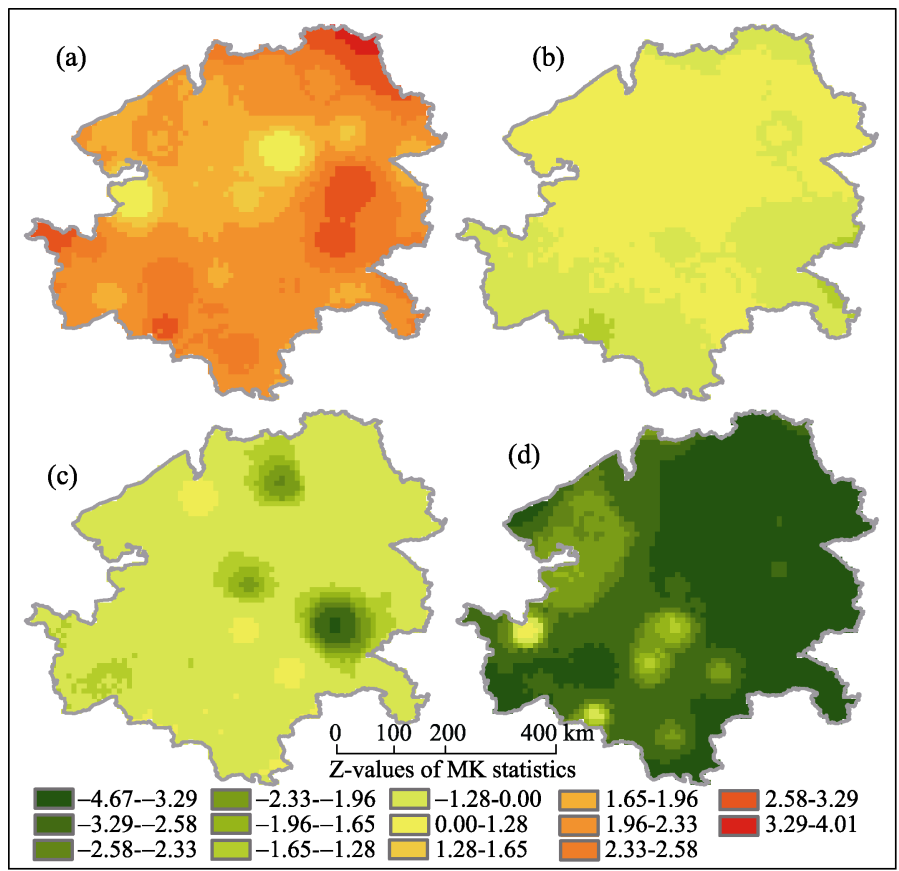

Figure 5 Trends of 4 main climate factors for growing season (May to October) by using Mann-Kendall (MK) trend test tool, where the $\mathrm{Z}$ value is denoted by the changing significance of climate factors. (a) mean temperature, (b) sunshine hours, (c) precipitation and (d) mean wind speed; positive values denote increase and negative values denote decrease over the period 1990-2015

values are higher in the central and southwestern regions (Figures 6a3, 6b3, 6a4 and 6b4). Marked gradients are evident in the patterns exhibited by some of the parameters. Especially prominent are the lower SOC values in the southwestern part of the plain, evident in both the 1990 and 2015 situations (Figures 6a1 and 6b1), a converse pattern repeated in the case of $\mathrm{pH}$ where soils in the southwest are considerably more alkaline with $\mathrm{pH}$ of 10 (Figures $6 \mathrm{a} 4$ and 6b4) than those to the north and east. Clay content also exhibits quite strong NE-SW contrasts, with much higher values $(\sim 50 \%)$ in the northern and eastern sectors (Figures $6 \mathrm{a} 2$ and $6 \mathrm{~b} 2)$, while bulk density values are higher $\left(1.5 \mathrm{~g} / \mathrm{cm}^{3}\right)$ in the west and southwest of the plain (Figure 6a3).

As for differences between 1990 and 2015, a decreasing trend in SOC (negative values) is observed across much of the Songnen Plain except for minor increases (positive values) in parts of the the south central, west and northwest areas. The most notable increase is in the northeast where a maximum of $0.0285 \mathrm{~kg} \mathrm{C} / \mathrm{kg}$ (Figure 6c1) was added over time. Large areas of the central plain exhibit a decreasing trend with respect to clay content, apart from several small areas of the southeast and north-central (Figure 6c2). Decreasing bulk density is apparent in the west (Figure 6c3). Soil pH substantially decreases for most areas although increases slightly in parts of the southwest, northwest and east-central regions (Figure 6c4).

\subsection{Changes in cropland use}

Over the past three decades, the Songnen Plain has experinced an observable change, one of most prominent manifestations is the conversion of land use types (Cui et al., 2015). The Songnen Plain, as a major agricultural production area, can be expected to reflect the impacts of environmental changes interacting national economic policy in China. 

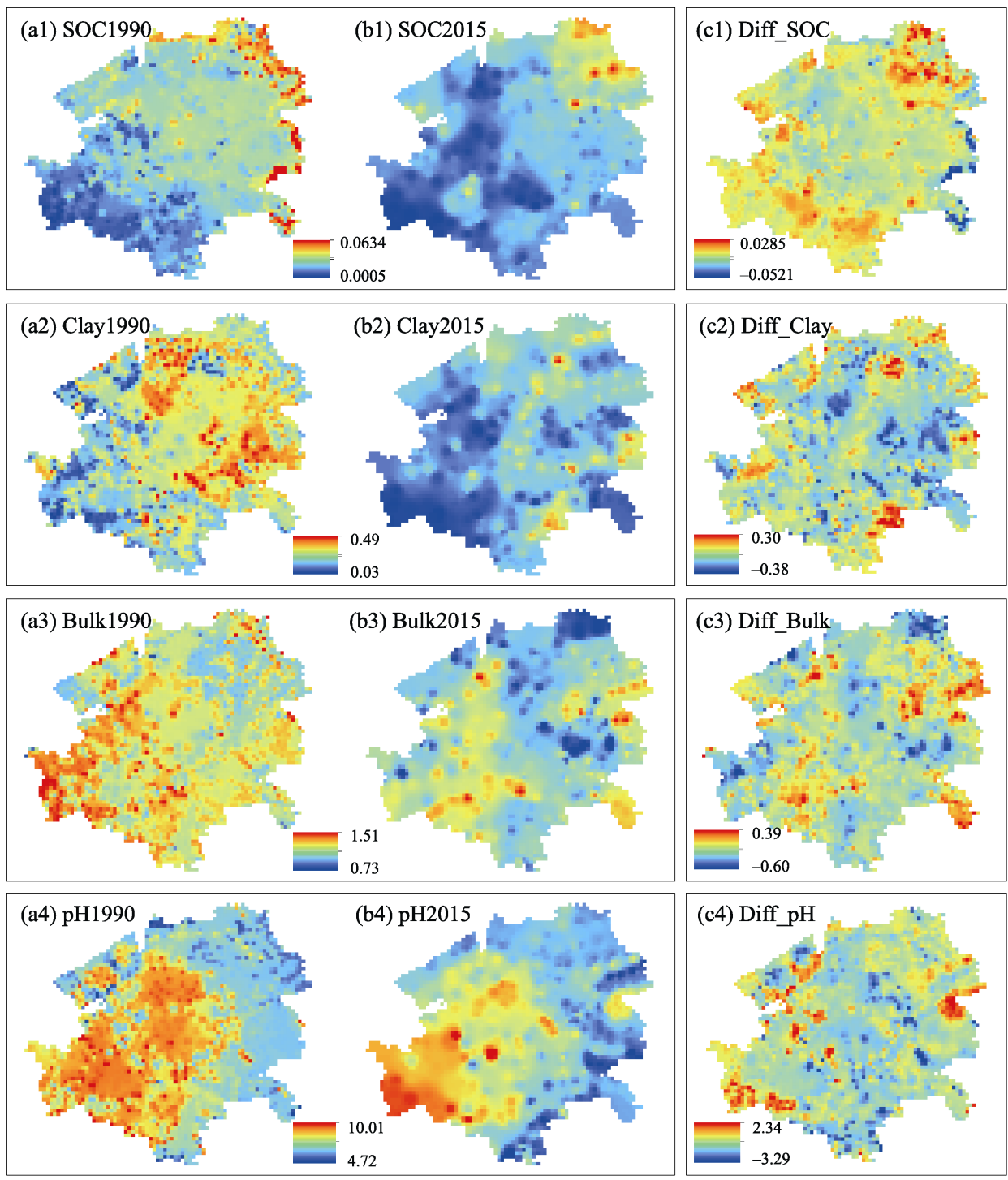

Figure 6 Spatial distribution of soil properties in 1990 and 2015, and their corresponding differences representing the increased (positive values) or decreased (negative values) trend in SOC, clay, bulk density and $\mathrm{pH}$

The distribution map of cropland shows the Songnen Plain has experienced a considerable cropland expansion since 1990 (Figure 7). The increased croplands are mainly derived from grassland and wetlands (Wang et al., 2011; Huang et al., 2012). Forested lands in the eastern parts of the region and grasslands in the southwestern have also decreased significantly during the period from 1990 to 2015. They are converted to dryland crop cultivation, an observed pattern that concurs with that reported by Liu et al. (2009). The major cropland types are paddy fields for rice and dryland for maize. Lowland rice has been increasing since the early 1990s, partly at the expense of decreasing dryland crops in the northwestern, west central and southeastern parts of the Songnen Plain (Figure 7). This is mainly attributed to the greater economic income from rice production compared to maize or soya (Liu et al., 2009; Gao and Liu, 2011). 


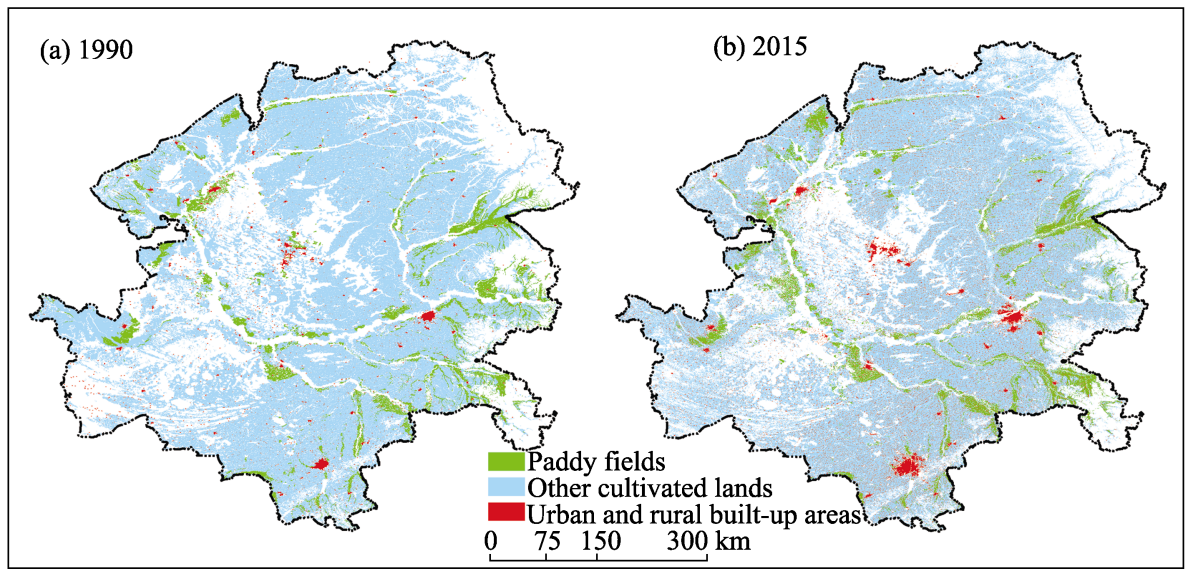

Figure 7 Spatial distribution of croplands (drylands and rice paddies) and built-up areas in 1990 and 2015

Agronomic statistics reveal these trends clearly, both sown areas of cropland and fertilizer applications in the Songnen Plain increased by $\sim 4$ million ha and $\sim 2.5$ million tons, respectively over the period 1990-2015 (Figure 8). From around the year 2000 onwards, the increase in sown area is especially marked (Figure 8a). Accordingly, the grain production increases over 44.0 million tons from 27.76 million tons in 1990 to 71.37 million tons in 2015 (Figure $8 \mathrm{~b}$ ). This substantial upturn in both sown area and grain production of croplands resulted from the widespread reclamation of grassland, woodland and wetlands, which was closely related to the rapid population growth and pursuit of economic benefits (Gao et al., 2006; Liu et al., 2009). In order to promote grain productivity, huge quantities of chemical fertilizer (now $>5$ million tons annually) are applied to the croplands of the region to provide the burgeoning population with grain in order to safeguard food security (Figure 8a). In fact, over the ten year period from 2005 to 2015, the rate of fertilizer consumption increase has exceeded the growth rate in cropped area (Figure 8a). Although this may have positive effects on annual grain yields (Figure 8b), such long-term excessive inputs of chemical fertilizer may have deleterious impacts on the soil biological, physical and chemical properties as have been reported elsewhere (Dong et al., 2014; Qu et al., 2014).

\section{Discussion}

\subsection{Effects of changing climate on croplands}

Some elements of the changing climate appear to have positive influences on agriculture, such as increased mean temperature and total precipitation which may have led to some of the more northerly or higher elevation areas becoming more favorable for cultivation. However, it is not only mean or total climate characteristics that determine the relative success or failure of croplands. For example, the more frequent occurrence of extreme events, such as heat waves, heavy rain/storms and floods, droughts are also important. Such hazards pose sig nificant challenges to agricultural production and in severe cases are associated with loss of livelihoods and possibly irreversible economic damage.

Since 1990, several extreme weather events have been recorded, such as the most severe flood event in the past 100 years that occurred in the summer of 1998 in the Songhuajiang 

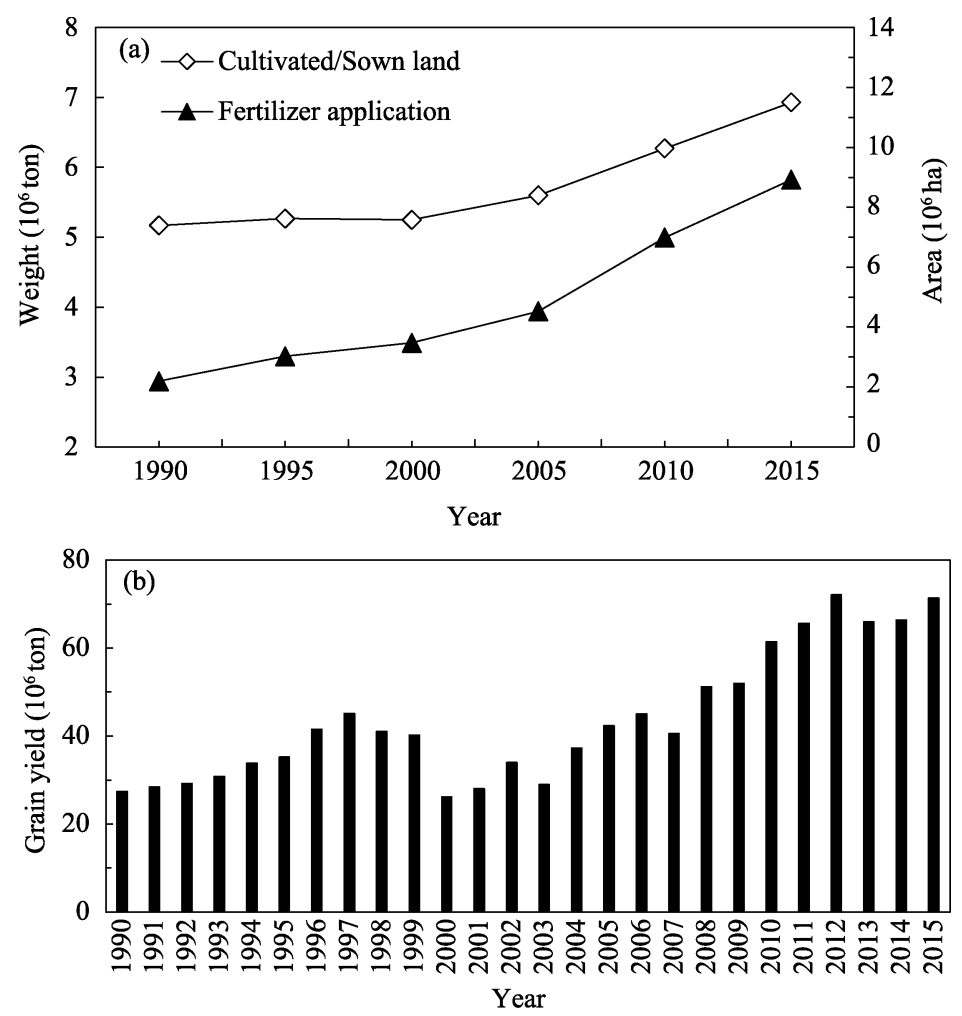

Figure 8 Agronomic statistics (total sown area, fertilizer inputs and grain output) in the Songnen Plain, from 1990 to 2015

and Nenjiang River catchments. In that year, the total precipitation in the Songnen Plain was $680 \mathrm{~mm}$, of which $637 \mathrm{~mm}$ were recorded between May and October (by far the highest recorded over the studied period). Drought is also a significant stressor; for example, northern China as a whole experienced extremely high temperatures and negative monthly precipitation anomalies in the summers of 2000 and 2001, resulting in reduced grain yields (Guo et al., 2017). In recent years, floods and droughts in the region have occurred with increasing frequency (Liu et al., 2014; Wang et al., 2015). There was another widespread drought in 2007 and severe flooding again in 2013.

It can be anticipated that greater frequency and magnitude of future extreme hydrometeorogical events as predicted by IPCC 2013 will exacerbate the vulnerability of the cropland ecosystem. This pose a serious challenge to grain production in the Songnen Plain, considering the likely future trajectory of climate conditions. Therefore, systematic strategy is needed to construct a cropland system that can be adapted to the changing climate conditions, and to ensure the system continues to operate effectively in the future.

\subsection{Variability in soil properties}

The top layer (A horizon) of a soil profile is most vulnerable and sensitive to environmental changes. Changes in such properties are a consequence of both natural and anthropogenic factors, e.g. climatic change, population increase, overgrazing, and intensive cultivation etc. 
Soil organic carbon plays important roles both in mitigating climate change (Lal, 2004) and in sustaining soil fertility. As noted in section 3.2, the declined SOC is evident for the entire Songnen Plain, while there are some small areas where SOC has actually increased, especially in the northeast (Figure 6c1). Indeed, this change has been reported previously for this part of the region, as Mao et al. (2014) noted the increased average SOC levels $(+0.56$ $\mathrm{kg} \mathrm{C} / \mathrm{m}^{2}$ ) between 1980 to 2010 attributed to the extensively adopted management practice of leaving crop residue in the field after harvest. Clearly, this demonstrates that introduction of appropriate soil and crop management practices, such as returning crop residue, manure application and less (or no-) tillage, can reduce SOC loss in croplands.

The decreasing trend in $\mathrm{pH}$ of soils across some areas of the plain suggests that there have been important developments in addressing soil salinization and alkalinization problems, these have been especially apparent in parts of Jilin Province (Wang et al., 2003; Jiang et al., 2010; Chi et al., 2012). However, for large area of saline-alkali lands remain in the western parts of the plain, there is a further risk that temperature and moisture changes may lead to more severe soil salinization (Yang et al., 2010; Wang and Li, 2013). These lands might be the potentially important agricultural resource for cropping. As such, this situation demands further study and implementation of appropriate management interventions.

\subsection{Cropland use changes with socioeconomic development and policy reform}

\subsubsection{Impacts and effects of policy reform on croplands}

Government policy reform has been a key factor driving land use changes in China as a whole (Ding, 2003). China's "economic reform and opening up" policy was initiated in the late 1980s. Since the "market economy" was implemented in 1992, some grasslands, sandy lands and abandoned farmlands have been reclaimed or reused by farmers for pursuing more economic benefits. The grain yield is closely related to the area of arable lands, the amount of agricultural inputs (e.g. water, fertilizer, etc.) and the efficiency of management practices. Along with the extension and intensification of agriculture, soil degradation, including accelerated loss of the topsoil and associated reduction in organic matter, has aroused concern for the protection of cropland resources (Chaplin-Kramer et al., 2015). In response to what was being touted as an environmental crisis, China launched the "Grain for Green" project, in 1999, a policy which appears to have had very positive results on soil carbon in many localities (Deng et al., 2014; Song et al., 2014b). Economic compensation provided by the government has stimulated farmers to return degraded cropland in particular to forestland or grassland. In addition, the increasing urban sprawl of recent years has seen many of the original croplands being expropriated for infrastructure construction in major cities of the region such as Changchun, Harbin, Daqing and Qiqihar (Figure 7). Cropland has been consumed in the process of constructing, for example, transport routes, including highways and the high-speed railway, industrial, commercial and residential areas but has also been consolidated through concentration of the dispersed rural population in a number of smaller urban centres (Liu et al., 2014). As a major national provider of commercial grain, the Songnen Plain is of considerable strategic importance to China. In the long run, effective sustainable management and scientific planning of the existing and future cropland resources will be essential to the productivity of agriculture in the region (Lu et al., 2015). 


\subsubsection{Outlook of cropland uses under future socioeconomic development}

Early in 2017, the central government enacted a new regulation to promote structural reforms in agriculture supply side (accessible at: http://politics.people.com.cn/n1/2017/0206/ c1001-29059337.html, in Chinese). The goal of this reform is to enhance the productivity of cropland and improve overall efficiency of the agricultural resource base. As part of the new strategy, agricultural regionalization is aimed at identifying several key production regions for major crops (e.g. rice, wheat, soya and maize) and to introduce evidence-based, informed cropland management systems. The new regulations may influence spatial distribution of major crops, including paddy rice, maize and soya in the Songnen Plain. A second element of the new regulations deals with the reclamation of degraded land in the agro-pastoral ecotone of northern China and includes projects to protect and restore natural wetlands and to return farmland to forest. In addition, efforts to protect the black soil regions of Northeast China are to be intensified with the aim of increasing SOC in the associated croplands. All of this implies that the cropland areas of the Songnen Plain will be under stricter control and that further expansion of cultivated areas will not be possible to meet the greater demands.

The national crop production base has to provide food consistently for a population of more than a billion people, and the plain will have to continue to play their part in meeting this demand. Alternatives such as increasing crop yield per unit area, improvements in soil fertility, selection of high-quality crop cultivars and the adoption of more scientific agronomic practices will need to be considered. The promotion of 'Smart Agriculture' (Xiong et al., 2014) is also a promising option for the future sustainability of cropland in the Songnen Plain.

\section{Conclusions}

A synthesis of multiple data sources for climate factors, soil physical properties and cropland use patterns, in combination with statistics on grain production and fertilizer application, were used in our study to characterize changes in ECC across the Songnen Plain, Northeast China, for the period 1990 to 2015. Major findings are listed below:

(1) Spatiotemporal analyses in climate conditions over the Songnen Plain during the period 1990-2015 indicated a clear increasing trend in mean temperature, especially in the growing season, while wind speed declined significantly. The changing rate of mean temperature and wind speed was $0.49^{\circ} \mathrm{C} /$ decade $(\mathrm{p}<0.05)$ and $0.3 \mathrm{~m} / \mathrm{s} / \mathrm{decade}(\mathrm{p}<0.01)$, respectively. The sunshing hours experienced an increase and then decrease process. In contrast, the precipitation represented a converse trend with first decrease and then increase trajectory. The increased temperature and precipitation have had positive influences on crop cultivation. This has been manifested in the increased area (7.39 million ha in 1990 to 11.50 million ha in 2015) of croplands in the northern part of the Songnen Plain. However, the increased frequency of floods and droughts proved to be major stress factors limiting crop production and grain yield.

(2) Change analysis in topsoil properties indicated that four major physical parameters showed generally decreasing trends for most croplands of the Songnen Plain, notwithstanding observable increases in a few of sparsely distributed areas. The changing amplitude ranges from -0.052 to $0.029 \mathrm{~kg} \mathrm{C} / \mathrm{kg},-0.38$ to $0.30,-0.60$ to $0.39 \mathrm{~g} / \mathrm{cm}^{3},-3.29$ to 2.34 for 
SOC, clay content, bulk density and $\mathrm{pH}$, respectively. The decline in SOC over large areas of croplands in the central plain to some extent could reduce soil fertility and further productivity of croplands. Otherwise, the increasing trends of $\mathrm{pH}$ in the western part of the Songnen Plain demands introduction of ameliorative measures to mitigate future aggravation and expansion of salinization in the region.

(3) Grain production significantly increased from 27.76 million tons in 1990 to 71.37 million tons in 2015 with increasing sown areas of croplands ( $\sim 4$ million ha) and fertilizer applications ( $\sim 2.5$ million tons). However, the continued expansion of cities and associated transportation infrastructure over the Songnen Plain is expected with the fast urbanization process in China. Present challenges is to protect the existing croplands and to maintain their capacity to provide sufficient grain for ensuring ongoing food security. Scientifically-based planning decisions for the croplands and the introduction and promotion of effective management practices are therefore of considerable importance.

In conclusion, the observed changes in environmental characteristics of cropland in the Songnen Plain may be attributed to a combination of natural and anthropogenic driving forces. The interplay of all environmental factors associated with the climate, soil and human intervention determines the dynamics over the period of 1990-2015 in the region.

\section{References}

Alvarez R, Lavado R S, 1998. Climate, organic matter and clay content relationships in the Pampa and Chaco soils, Argentina. Geoderma, 83: 127-141.

Bakker M M, Hatna E, Kuhlman T et al., 2011. Changing environmental characteristics of European cropland. Agricultural Systems, 104(7): 522-532.

Bohlen P J, House G, 2009. Sustainable Agroecosystem Management: Integrating Ecology, Economics, and Society. Boca Raton: CRC Press.

Burke I C, Yonker C M, Parton W J et al., 1989. Texture, climate, and cultivation effects on soil organic matter content in U.S. grassland soils. Soil Science Society of America Journal, 53(3): 800-805.

Chaplin-Kramer R, Sharp R P, Mandle, L et al., 2015. Spatial patterns of agricultural expansion determine impacts on biodiversity and carbon storage. PNAS, 112(24): 7402-7407.

Chen C Q, Lei C X, Deng A X et al., 2011. Will higher minimum temperatures increase corn production in Northeast China? An analysis of historical data over 1965-2008. Agricultural and Forest Meteorology, 151(12): 1580-1588.

Chen X Q, Hu B, Yu R, 2005. Spatial and temporal variation of phenological growing season and climate change impacts in temperate eastern China. Global Change Biology, 11: 1118-1130.

Chi C M, Zhao C W, Sun X J et al., 2012. Reclamation of saline-sodic soil properties and improvement of rice (Oriza sativa L.) growth and yield using desulfurized gypsum in the west of Songnen Plain, northeast China. Geoderma, 187/188: 24-30.

Cui X, Zhu W, Xu X et al., 2015. Land-use Changes in China: Historical Reconstruction Over the Past 300 Years and Future Projection. Danvers: World Scientific.

Dai W, Huang Y, 2006. Relation of soil organic matter concentration to climate and altitude in zonal soils of China. Catena, 65(1): 87-94.

Deng L, Liu G B, Shangguan Z P et al., 2014. Land use conversion and changing soil carbon stocks in China's 'Grain-for-Green' Program: A synthesis. Global Change Biology, 20: 3544-3556.

Ding C R, 2003. Land policy reform in China: Assessment and prospects. Land Use Policy, 20(2): 109-120.

Dong W Y, Zhang X Y, Dai X Q et al., 2014. Changes in soil microbial community composition in response to fertilization of paddy soils in subtropical China. Applied Soil Ecology, 84: 140-147.

Fantappiè M, L'Abate G, Costantini E A C, 2011. The influence of climate change on the soil organic carbon content in Italy from 1961 to 2008. Geomorphology, 135 (3/4): 343-352.

Gao J, Liu Y S, Chen Y F, 2006. Land cover changes during agrarian restructuring in Northeast China. Applied Geography, 26: 312-322.

Gao J, Liu Y S, 2011. Climate warming and land use change in Heilongjiang Province, Northeast China. Applied Geography, 31: 476-482.

Guo E, Liu X, Zhang J et al., 2017. Assessing spatiotemporal variation of drought and its impact on maize yield in 
Northeast China. Journal of Hydrology, 553(Suppl. C): 231-247.

Heilongjiang Statistical Bureau (HSB), 2016. Heilongjiang Statistical Yearbook 2016. Beijing: China Statistics Press. (in Chinese)

Hillel D, Rosenzweig C, 2011. Handbook of Climate Change and Agroecosystems: Impacts, Adaptation, and Mitigation. London: Imperial College Press.

Hillel D, Rosenzweig C, 2013. Handbook of Climate Change and Agroecosystems: Global and Regional Aspects and Implications. London: Imperial College Press.

Hirsch R M, Slack J R, Smith R A et al., 1982. Techniques for trend analysis for monthly water quality data. Water Resources Research, 18(1): 107-121.

Homann P S, Kapchinske J S, Boyce A, 2007. Relations of mineral-soil C and N to climate and texture: Regional differences within the conterminous USA. Biogeochemistry, 85(3): 303-316.

Huang F, Wang P, 2010. Vegetation change of ecotone west of Northeast China Plain using time-series remote sensing data. Chinese Geographical Science, 20(2): 167-175.

Huang F, Wang P, Zhang J, 2012. Grasslands changes in the northern Songnen Plain, China during 1954-2000. Environmental Monitoring and Assessment, 184(4): 2161-2175.

IPCC (Intergovernmental Panel on Climate Change), 2007. Climate Change 2007: The Physical Science Basis. Contribution of Working Group I to the Fourth Assessment Report of the Intergovernmental Panel on Climate Change. London: Cambridge University Press.

IPCC (Intergovernmental Panel on Climate Change), 2013. Climate Change 2013: The Physical Science Basis. Contribution of Working Group I to the Fifth Assessment Report of the Intergovernmental Panel on Climate Change. London: Cambridge University Press.

Jiang L, Zhang L, Zang S et al., 2016. Accuracy assessment of approaches to spatially explicit reconstruction of historical cropland in Songnen Plain, Northeast China. Journal of Geographical Sciences, 26(2): 219-229.

Jiang S C, He N P, Wu L et al., 2010. Vegetation restoration of secondary bare saline-alkali patches in the Songnen Plain, China. Applied Vegetation Science, 13(1): 47-55.

Jilin Statistical Bureau (JSB), 2016. Jilin Statistical Yearbook 2016. Beijing: China Statistics Press. (in Chinese)

Jobággy E G, Jackson R B, 2000. The vertical distribution of soil organic carbon and its relation to climate and vegetation. Ecological Applications, 10(2): 423-436.

Kendall M G, 1975. Rank Correlation Methods. London: Charles Griffin.

Lal R, 2004. Soil carbon sequestration to mitigate climate change. Geoderma, 123(1): 1-22.

Leipnik M, Su Y, Ye X, 2014. The main agricultural regions of China and the U.S. A Comparative Geography of China and the U.S. Hartmann R and Wang J (eds.). New York: Springer.

Li Z, Tang H, Yang P et al., 2012. Spatio-temporal responses of cropland phenophases to climate change in Northeast China. Journal of Geographical Sciences, 22(1): 29-45.

Liu D, Wang Z, Song K et al., 2009. Land use/cover changes and environmental consequences in Songnen Plain, Northeast China. Chinese Geographical Science, 19(4): 299-305.

Liu S, Zhang P, Lo K, 2014. Urbanization in remote areas: A case study of the Heilongjiang reclamation area, Northeast China. Habitat International, 42: 103-110.

Liu Z, Dong X, Liu Z, 2014. Spatiotemporal evolution of the drought and flood in Northeast China. Advanced Materials Research, 1010-1012: 1075-1083.

Lu R K, 2000. Analytical Method of Soil Agricultural Chemistry. Beijing: China Agricultural Science and Technology Press. (in Chinese).

Lu Y, Jenkins A, Ferrier R C et al., 2015. Addressing China's grand challenge of achieving food security while ensuring environmental sustainability. Science Advances, 1(1): e1400039.

Mann H B, 1945. Nonparametric tests against trend. Econometrica, 13(3): 245-259.

McPhaden M J, 1999. Genesis and evolution of the 1997-98 El Niño. Science, 283(5404): 950-954.

Mao D, Wang Z, Wu C et al., 2014. Topsoil carbon stock dynamics in the Songnen Plain of Northeast China from 1980 to 2010. Fresenius Environmental Bulletin, 23(2A): 531-539.

Meng Q, Li D, Zhang J et al., 2016. Soil properties and corn (Zea mays L.) production under manure application combined with deep tillage management in solonetzic soils of Songnen Plain, Northeast China. Journal of Integrative Agriculture, 15(4): 879-890.

National Bureau of Statistics of China (NBSC), 2016. China Statistical Yearbook 2016. Beijing: China Statistics Press.

Périé C, Ouimet R, 2008. Organic carbon, organic matter and bulk density relationships in boreal forest soils. Canadian Journal of Soil Science, 88(3): 315-325.

Piao S L, Fang, J Y, Ciais P et al., 2009. The carbon balance of terrestrial ecosystems in China. Nature, 458: 1009-1014.

Podwojewski P, Poulenard J, Nguyet M L et al., 2011. Climate and vegetation determine soil organic matter status in an alpine inner-tropical soil catena in the Fan Si Pan Mountain, Vietnam. Catena, 87(2): 226-239.

Qiu X, Zhang L, Li W et al., 2016. Studies on changes and cause of the minimum air temperature in Songnen Plain of China during 1961-2010. Acta Ecologica Sinica, 36(5): 311-320. 
Quideau S, Chadwick O A, Benesi A et al., 2001. A direct link between forest vegetation type and soil organic matter composition. Geoderma, 104(1/2): 41-60.

Richter D D, Houghton R A, 2011. Gross $\mathrm{CO}_{2}$ fluxes from land-use change: Implications for reducing global emissions and increasing sinks. Carbon Management, 2(1): 41-47.

Schauberger B, Archontoulis S, Arneth A et al., 2017. Consistent negative response of US crops to high temperatures in observations and crop models. Nature Communications, 8: 13931.

Shepard D, 1968. A two-dimensional interpolation function for irregularly-spaced data. Proceedings of the $23 \mathrm{rd}$ Association for Computing Machinery (ACM) National Conference. New York: ACM, 517-524.

Shi X Z, Yu D S, Warner E D et al., 2004. Soil database of 1:1,000,000 digital soil survey and reference system of the Chinese genetic soil classification system. Soil Survey Horizons, 45(4): 129-136.

Song X, Li L, Fu G et al., 2014a. Spatial-temporal variations of spring drought based on spring-composite index values for the Songnen Plain, Northeast China. Theoretical and Applied Climatology, 116(3/4): $371-384$.

Song X, Peng C, Ghou G et al., 2014b. Chinese Grain for Green Program led to highly increased soil organic carbon levels: A meta-analysis. Scientific Reports, 4: 4460.

Tan J, Yang P, Liu Z et al., 2014. Spatio-temporal dynamics of maize cropping system in Northeast China between 1980 and 2010 by using spatial production allocation model. Journal of Geographical Sciences, 24(3): 397-410.

Tilman D, Cassman K G, Matson P A et al., 2002. Agricultural sustainability and intensive production practices. Nature, 418: 671-677.

Wagai R, Mayer L M, Kitayama K et al., 2008. Climate and parent material controls on organic matter storage in surface soils: A three-pool, density-separation approach. Geoderma, 147(1/2): 23-33.

Wang D D, Shi X Z, Wang H J et al., 2010a. Scale effect of climate and soil texture on soil organic carbon in the uplands of Northeast China. Pedosphere, 20(4): 525-535.

Wang H, Wan Z, Yu S et al., 2004. Catastrophic eco-environmental change in the Songnen Plain, northeastern China since 1900s. Chinese Geographical Science, 14(2): 179-185.

Wang X, Shen H, Zhang W et al., 2015. Spatial and temporal characteristics of droughts in the Northeast China Transect. Natural Hazards, 6(1): 601-614.

Wang Y, Li Y, 2013. Land exploitation resulting in soil salinization in a desert-oasis ecotone. Catena, 100: 50-56.

Wang Z, Huang N, Luo L et al., 2011. Shrinkage and fragmentation of marshes in the West Songnen Plain, China, from 1954 to 2008 and its possible causes. International Journal of Applied Earth Observation and Geoinformation, 13(3): 477-486.

Wang Z, Li Q, Li X et al., 2003. Sustainable agriculture development in saline-alkali soil area of Songnen Plain, Northeast China. Chinese Geographical Science, 13(2): 171-174.

Wang Z, Zhang B, Song K et al., 2010b. Spatial variability of soil organic carbon under maize monoculture in the Song-Nen Plain, Northeast China. Pedosphere, 20(1): 80-89.

Wen B, Liu X, Li X et al., 2012. Restoration and rational use of degraded saline reed wetlands: A case study in western Songnen Plain, China. Chinese Geographical Science, 22(2): 167-177.

Wu H B, Guo Z T, Peng C H, 2003. Distribution and storage of soil organic carbon in China. Global Biogeochemical Cycles, 17(2): 1048-1058.

Xia X, Yang Z, Liao Y et al., 2010. Temporal variation of soil carbon stock and its controlling factors over the last two decades on the southern Song-nen Plain, Heilongjiang Province. Geoscience Frontiers, 1(1): $125-132$.

Xie Z, Zhu J, Liu G et al., 2007. Soil organic carbon stocks in China and changes from 1980s to 2000s. Global Change Biology, 13(9): 1989-2007.

Xiong W, van der Velde M, Holman P et al., 2014. Can climate-smart agriculture reverse the recent slowing of rice yield growth in China? Agriculture, Ecosystems and Environment, 196: 125-136.

Yang J, Zhang S, Li Y et al., 2010. Dynamics of saline-alkali land and its ecological regionalization in western Songnen Plain, China. Chinese Geographical Science, 20(2): 159-166.

Yu D S, Shi X Z, Wang H J et al., 2007. Regional patterns of soil organic carbon stocks in China. Journal of Environmental Management, 85(3): 680-689.

Zhang B, Cui H S, Yu L et al., 2003. Land reclamation process in northeast China since 1900. Chinese Geographical Science, 13(2): 119-123.

Zhang L, Wang Y H, 2014. Study on the effects of economic growth to farmland conversion in China. Open Journal of Social Sciences, 2: 25-29.

Zhuang Q L, Li Q, Jiang Y et al., 2007. Vertical distribution of soil organic carbon in agro-ecosystems of Songliao plain along a latitudinal gradient. American-Eurasian Journal of Agricultural and Environmental Science, 2(2): $127-132$.

Zhou X, Zhou L, Nie Y et al., 2016. Similar responses of soil carbon storage to drought and irrigation in terrestrial ecosystems but with contrasting mechanisms: A meta-analysis. Agriculture, Ecosystems and Environment, 228: 70-81. 